\title{
Primary Infertility and Azoospermia Due to Congenital Bilateral Absent Vas Deferens in the Presence of a Solitary Kidney
}

\author{
Amer Karim \\ Senior House Surgeon, Institute of Urology, London \\ E-mail: amerkarim@e320.freeserve.co.uk \\ Published June 18, 2004
}

DOMAIN: urology

\section{CASE REPORT}

A 27-year-old gentleman referred with azoospermia and a normal hormone profile was shown on MRI examination to have an absent left ureter and seminal vesicle (Fig. 1). His subsequent IVU showed that his left kidney was also absent (Fig. 2).

He was diagnosed with congenital absence of vas deferens (CAVD) and was successfully treated with percutaneous sperm aspiration and subsequent IVF therapy.

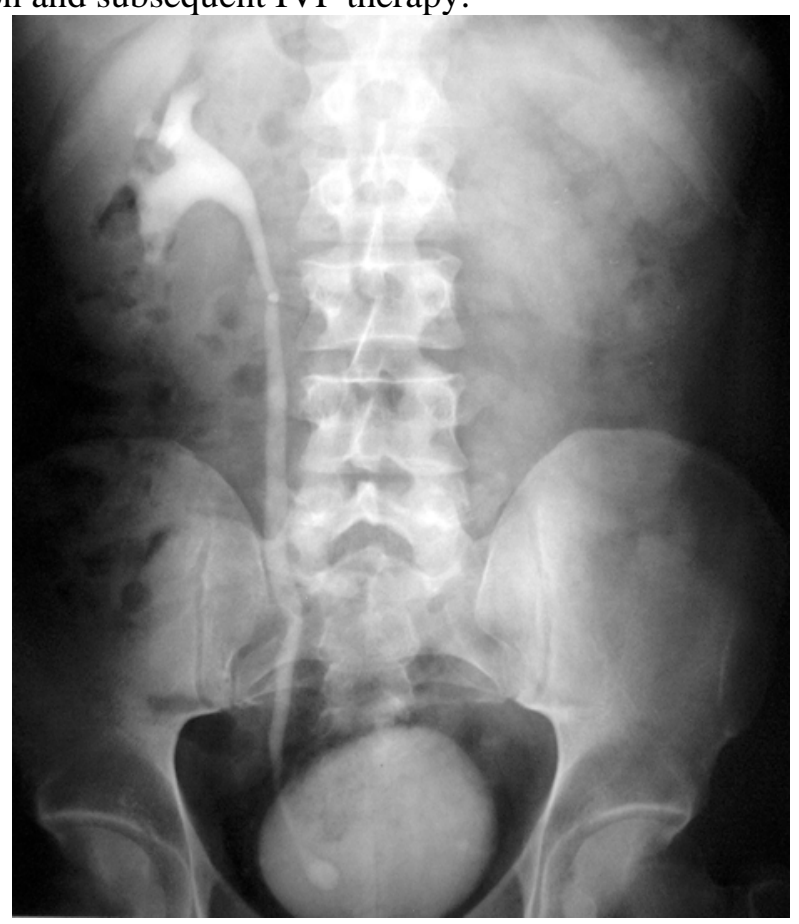

FIGURE 1. IVU demonstrating single right kidney. 


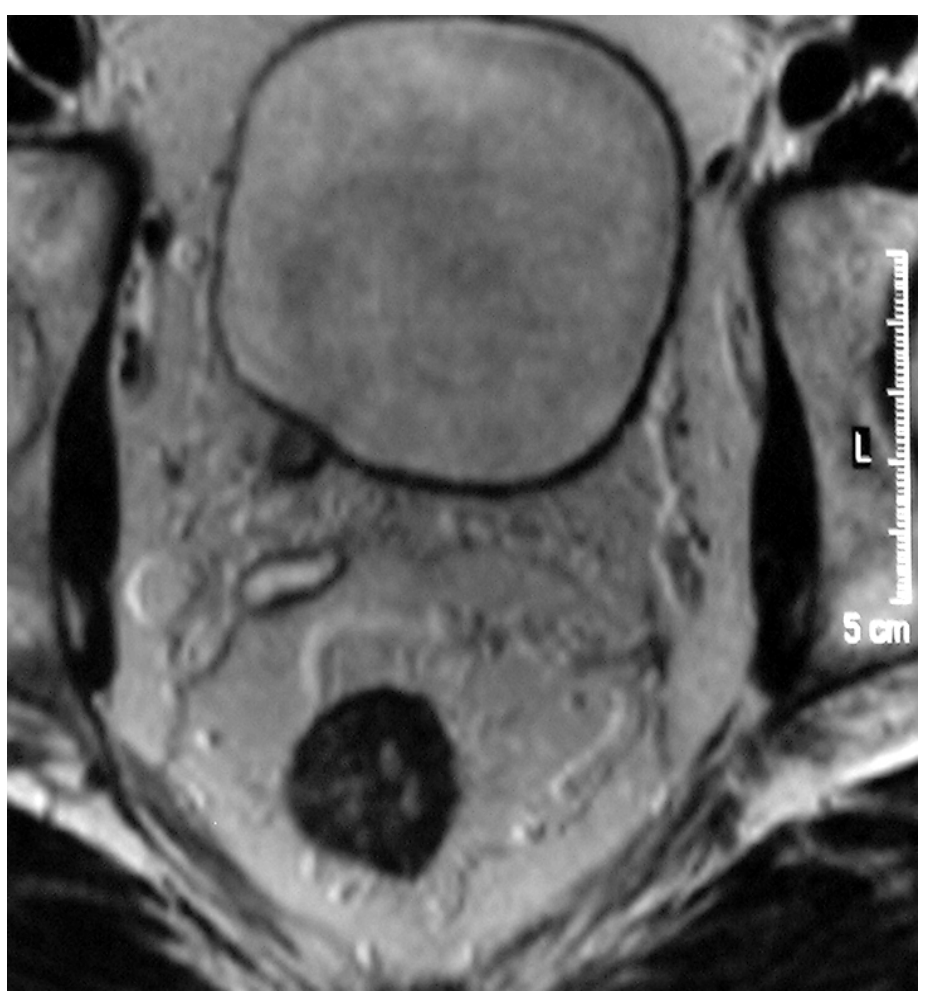

FIGURE 2. MRI demonstrating absent left seminal vesicle and ureter.

\section{COMMENTS}

CAVD is a syndrome in which a portion or all of the vas deferens, epididymis, and seminal vesicles are absent, either unilaterally or bilaterally[1]. It is the cause for approximately $1-2 \%$ of male infertility and $10 \%$ of ductal obstruction[2]. CAVD is an inherited condition, associated with heterozygous presence of one of the gene anomalies causing cystic fibrosis on chromosome. As in this case, $15 \%$ of patients with CAVD will also have a missing or ectopic kidney. Testicular size is usually normal, the distended caput epididymis may be palpable (Bayle's sign), and no vas is palpable within the spermatic cord. Spermatogenesis is usually normal.

\section{REFERENCES}

1. Shafik, A. (1996) Electrovasogram in patients with obstructive azoospermia and absent vas deferens. World J. Urol. 14(6), 393-396.

2. Della Morte, E., Capellano, F., and Cantanzo, F. (1996) Role and current significance of EDVG (epididymography plus vasography) in obstructive azoospermia. Arch. Ital. Urol. Androl. 68(5), 367-372. [Italian]

\section{This article should be referenced as follows:}

Karim, A. (2004) Primary infertility and azoospermia due to congenital bilateral absent vas deferens in the presence of a solitary kidney. TheScientificWorldJOURNAL 4, 458-459.

\section{Handling Editor:}

Anthony Atala, Principle Editor for Urology — a domain of TheScientificWorldJOURNAL. 


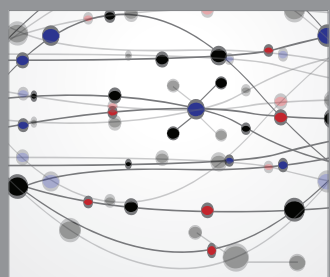

The Scientific World Journal
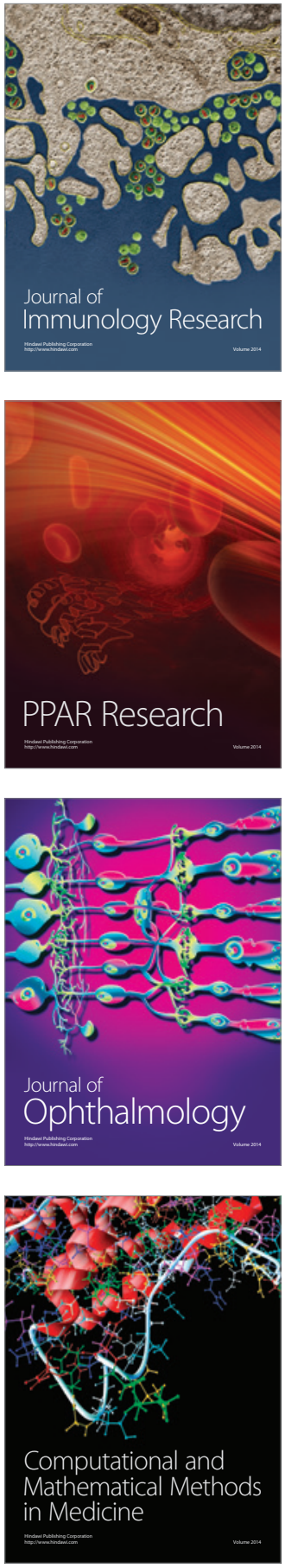

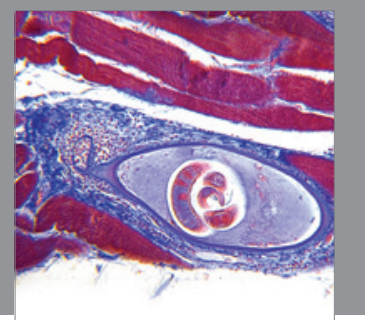

Gastroenterology

Research and Practice
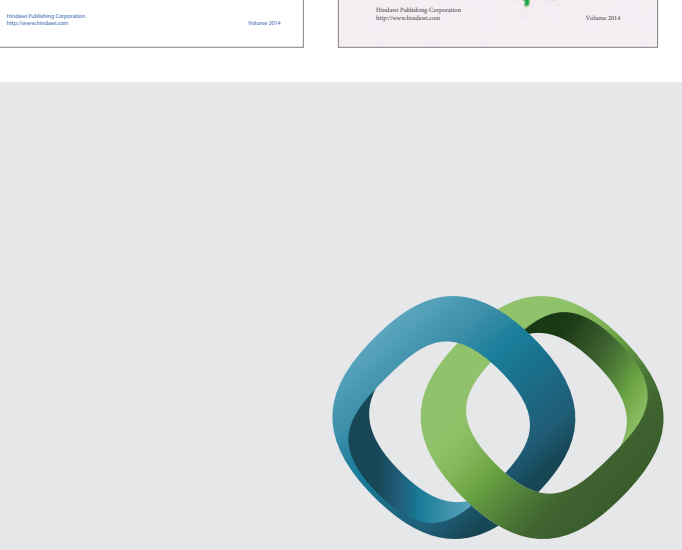

\section{Hindawi}

Submit your manuscripts at

http://www.hindawi.com
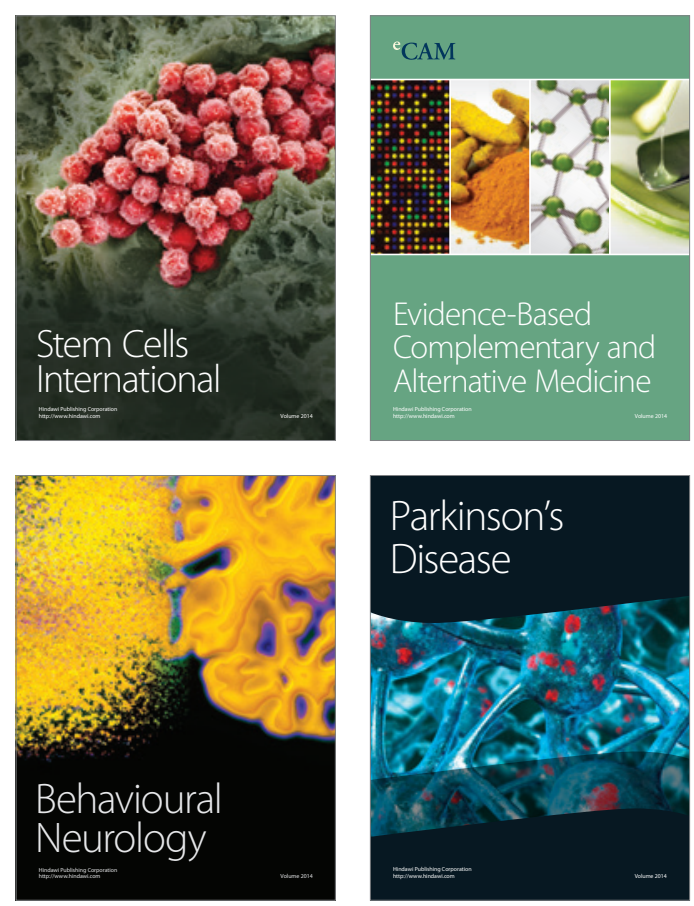

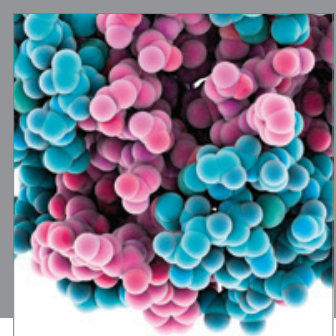

Journal of
Diabetes Research

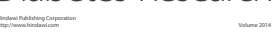

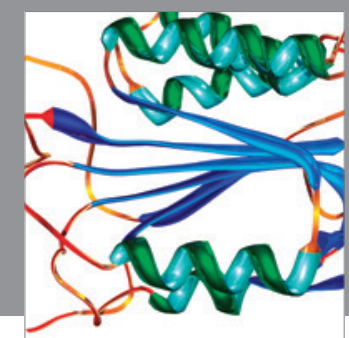

Disease Markers
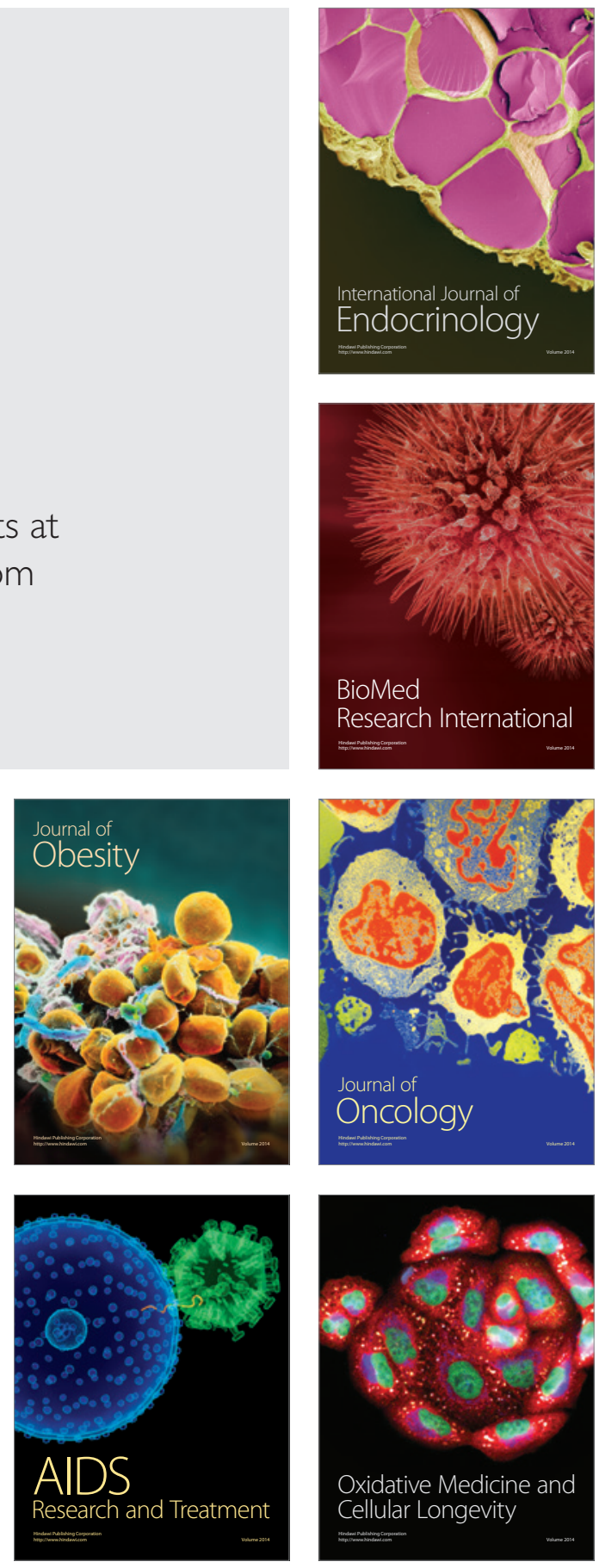